\title{
Port Elizabeth's tertiary care reaches crisis point
}

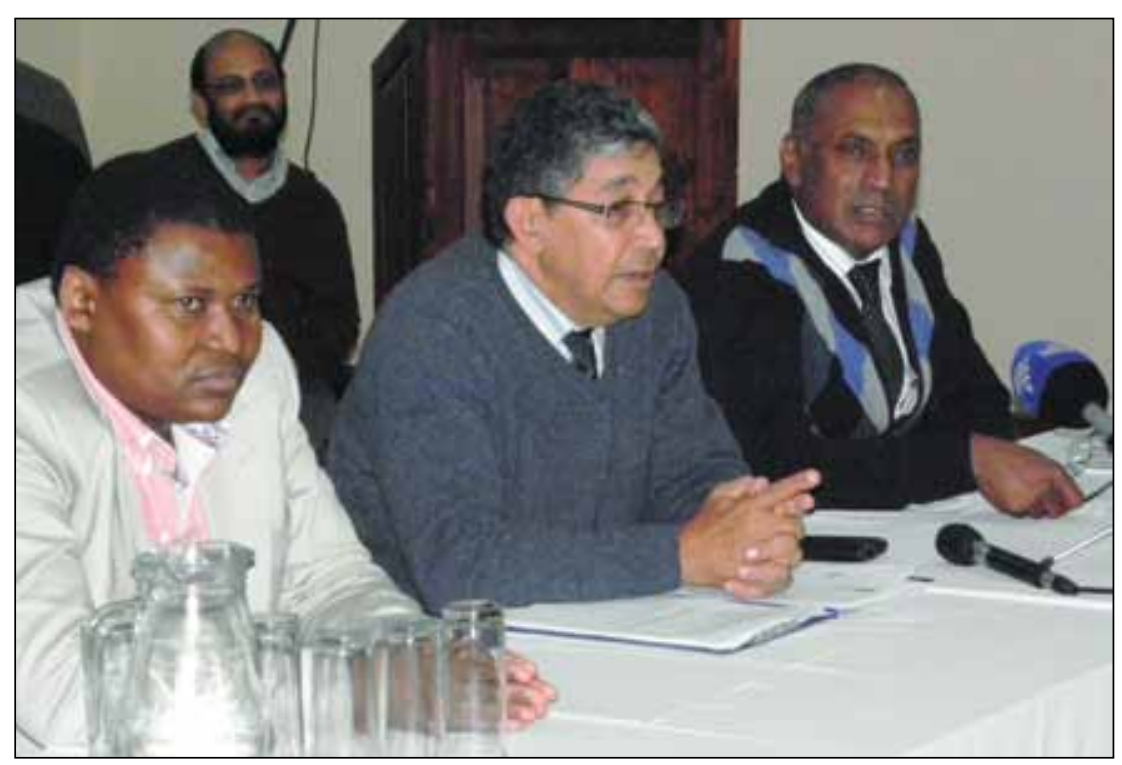

L - R: Dr Lungile Pepeta, Paediatric Chief at Dora Nginza Hospital, Dr Basil Brown, Cardiology Chief at Port Elizabeth Provincial Hospital and Professor Sats Pillay, Head of Surgery at Livingstone Hospital, at their 'rebel' Port Elizabeth press conference on 26 June this year.

Almost across disciplines, health care in the Port Elizabeth Provincial Hospital Complex (PEPHC) has deteriorated so badly in the past six months that short-staffed departmental heads are unapologetically cutting back on vital patient services to focus only on the very sick and dying.

The confrontation has its roots in posts not filled over the past six months by a corruptiondriven and dysfunctional provincial health department struggling to address a R2.5 billion budget shortfall.

When they held a joint press conference to announce this on 26 June, Head Office at Bhisho responded by demanding reasons from three of the most senior specialists as to why they had spoken to media without following protocols, threatening possible charges. A provincial health spokesman added colourfully: 'They've acted as if the department is a banana department'. The strong response is unlikely to lead to any official hearings because of an almost unanimous professional and civic outcry country-wide since. Eastern Cape Health Director General, Dr Siva Pillay, angered at the bypassing of him and the direct approach to Premier Noxolo Kieviet, told Izindaba the specialists had not used any of the regular avenues, including the public service commission, public service monitor, the bargaining council or the labour court. While conceding that their concerns were 'genuine, legitimate and serious', he said the picture painted was 'not entirely accurate. The confrontation has its roots in posts not filled over the past six months by a corruption-riven and dysfunctional provincial health department struggling to address a R 2.5 billion budget shortfall.

Izindaba has in its possession urgent letters to their superiors from the heads of Emergency Medicine, Paediatrics, Neurology, Ear Nose and Throat (ENT), Anaesthetics, Oncology, Urology, Surgery, Orthopaedics and Ophthalmology, begging for vacant PEPHC posts to be filled and detailing golden staffing opportunities missed through administrative inaction. More importantly, the chiefs outline how this is having a debilitating and far-reaching effect on service delivery, doctor training and staff morale. The hospital complex comprises Port Elizabeth Provincial, Dora Nginza and Livingstone hospitals. Their incapacity is aggravating dysfunction at the already hard-pressed network of district hospitals and clinics that rely on them exclusively for referral - with potentially fatal effects when inter-disciplinary care is required. When Dr Siva Pillay was shown the letters by Izindaba, he expressed the 'utmost respect' for 'most' of the specialists who were 'fighting a genuine battle that needs to be fought.' However, he said, had they spoken to him, they would have learnt that he had smoothed out the human resource process 'so that we can now fast-track appointments', and that his recent intervention with national treasury had led to a resetting of his health budget to include the R1.5 billion in overdraft and unauthorised expenditure previously earmarked for immediate repayment. In terms of recent political manoeuvring, a provincial co-ordinating and monitoring team now vets all appointments and provincial treasury has taken over the PERSAL (personnel salary) function and, said Pillay: 'They don't understand the urgency of it. ${ }^{1}$

\section{Dual loyalties again to the fore}

Professor Sats Pillay, Head of Surgery at Livingstone Hospital, who received warning letters together with Dr Lungile Pepeta, Paediatric Chief at Dora Nginza Hospital and Dr Basil Brown, Cardiology Chief at Port Elizabeth Provincial Hospital, said local management and head office failed to respond to 'repeated submissions and warnings' about the collapse of basic services resulting in sub-standard and unsafe care of patients. In his formal response (demanded within 48 hours) Pillay, a veteran surgeon, wrote that his actions were 'based purely on frustration'.

When Dr Siva Pillay was shown the letters by Izindaba, he expressed the 'utmost respect' for 'most' of the specialists who were 'fighting a genuine battle that needs to be fought'. However, he said, had they spoken to him, they would have learnt that he had smoothed out the human resource process 'so that we can now fast-track appointments'.

'My unwavering stance is that the welfare of my patients supersedes my obligation 
to obey the instructions of my employer as I am committed to the ethics and morality of my profession and conscience,' he said. In a flood of letters to their superiors from 20 to 22 June this year, the departmental chiefs complain about how disgruntled applicants, many of them ideal for posts, take jobs elsewhere after waiting for months to hear from head office in Bhisho. Pepeta (at Dora Nginza Hospital) writes that he lost five medical officers from January to July this year yet has seen no replacements, while a specialist who applied in April (without reply) had since taken up a post at Chris Hani Baragwanath Hospital in Gauteng. Pepeta baldly states under the cross-heading Resolution: 'As from July 1st (2012), our department will not be able to provide after hour services (emergency services) on certain days. Outpatient services, including specialist clinic services, will be reduced as priority will be given to very sick inpatients.'

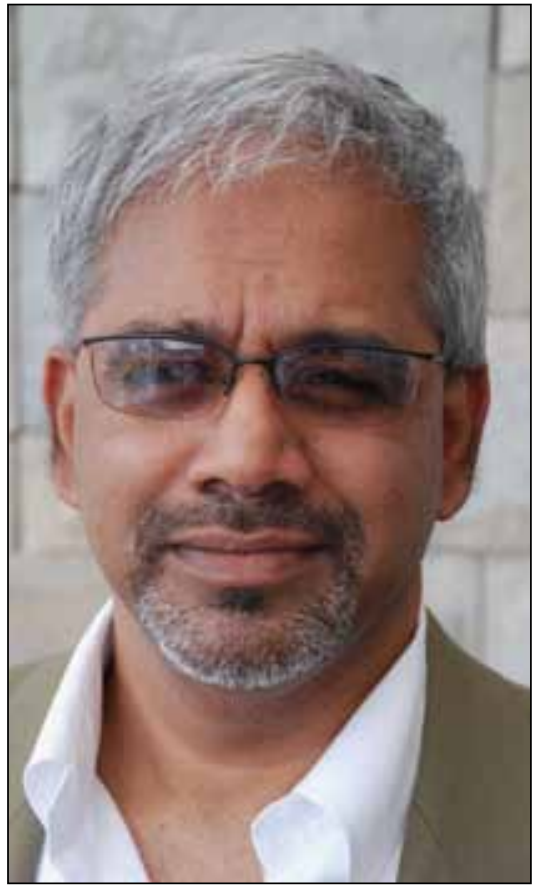

Eastern Cape Health Director General, Dr Siva Pillay.

Picture: Chris Bateman

\section{Tertiary institutions slowly stripped of staff}

Sats Pillay told Izindaba that Bhisho had tried over the last six months to address its financial travails by stripping (via attrition) healthcare professionals crucial to the tertiary service platform. 'They're unable to fire people in the bloated administration until they retire at 65 , so instead they simply don't re-appoint clinical staff, regardless of consequences to patient care.
He said the PEPHC had just over 240 doctors to service about 1100 'viable' patient beds, but emphasised that this included some 90 interns and 20 community service officers (Comserves) undergoing training. 'Nearly all the Comserves are being taken out and put into the countryside (district hospitals and clinics). We have to deal with all the resulting complications as they struggle on mostly unsupervised,' he added. 'The authorities' assertion that we have too many doctors in the complex is thus wrong, he added. His DG, Siva Pillay, immediately took issue, saying there were actually 312 doctors plus 41 sessional doctors for 1300 beds in the three PE hospitals. He juxtaposed this with the 97 doctors for the surrounding Cacadu region (the sprawling mainly rural area west of Port Elizabeth) which had 17 (district) hospitals and 1600 beds, explaining: 'We have a target to fill the positions at district hospitals first. Yes, PEPHC is short-staffed but they've been in worse situations and it's not as grave as they present it. They must re-orientate their business. There are even less doctors in East London (than in PE) - for more beds!'

Dr Sats Pillay (no relation), said the muchtouted and heavily equipped acute 'trauma unit' in his department, set up for the Fifa World Cup and subsequently converted into an 'acute surgical unit' - the first of its kind in the country - had deteriorated into a 'glorified casualty unit since they took all the staff away in January'. Again, Siva Pillay labelled this 'a misrepresentation'. 'They could have formed a team and converted it into a training school for trauma specialists, thus qualifying for a national treasury in-service training grant, but they messed it up, creating a problem, he countered.

\section{Patients were waiting for up} to a month to have a fractured ankle fixed, a year for a prostate operation or elective paediatric surgery while no spinal surgery was being done. There was no ENT surgeon for the entire PEPHC after one who had travelled from Frere Hospital in East London went unpaid for seven months and stopped coming.

Sats Pillay said patients were waiting for up to a month to have a fractured ankle fixed, a year for a prostate operation or elective paediatric surgery while no spinal surgery was being done. There was no ENT surgeon for the entire PEPHC after one who had travelled from Frere Hospital in East London went unpaid for seven months and stopped coming. A replacement identified and given appointment papers for 1 July was told the post was frozen after he arrived for work.

Once the controversy broke, a briefing by Sats Pillay and his colleagues of the provincial parliamentary health portfolio committee and various community leaders resulted in 'wide eyes and dropped jaws', Sats Pillay added. 'The administration obviously does not have any concept of what a tertiary service or teaching hospital is or what staffing levels should be - we have singleconsultant departments as exemplified by Urology, Paediatric Surgery, Plastic Surgery, Oncology, Neurosurgery, Nephrology and Medicine. Neurosurgery is one of the busiest sub-specialty departments and is being run by a retired specialist with help from a Johannesburg-based consultant who operates here once a week - and who has not been paid for the past six months.

Dr Gerda Wahl, Head of Neurology at the PE Provincial Hospital, is the last consultant standing in her department. She's supported by a registrar rotating from Internal Medicine and writes to her superior that she's been on call every other day and every other weekend for the past two months. 'What's more is that I do not have time to teach these registrars and feel that the training does not fulfil the standards set by the HPCSA for registrars. The two of us see the same number of patients at my neurology clinic as what is seen at other state institutions by between three consultants and four other registrars. Honestly, you can see the strain we are under to help our patients. I basically do the job of an intern, medical officer and consultant.' Wahl says the academic programme has collapsed and regular meetings with Internal Medicine, Neurosurgery, Radiology and Psychiatry have had to give way to service delivery. Clinics lasted too long to attend any meeting and intern training was non-existent. 'I truly feel guilty that we cannot consolidate the practical management of conditions like epilepsy and stroke, conditions that are so prevalent when they (the interns) go out to serve our community in the peripheral hospitals during their community service year.' The pressure was such that she had hardly any time for conduction studies and electromyelograms without medical officers on hand.

\section{Another hopeful specialist waits in vain}

What pained her most was an electrophysiologist who had waited for an appointment since January this year, first 
for three months at home and then taking an interim job in another province to make ends meet. The interim job soon became a permanent one. Wahl's other plans like setting up a stroke unit, contributing to the Paediatric Neurology Clinic and reaching out to the bigger referral centres like Uitenhage, Grahamstown and East London had become, 'well ... just plans'. Acting head of the ENT department at PEPHC, Dr S Soga, says his department has never had a full-time specialist since inception while visits by specialists from East London had stopped because their contracts were not renewed. Because of this, pre-booked cases for surgery were postponed indefinitely, cases booked for specialist opinion got no such attention and urgent paediatric cases needing specialist care had to be directed straight to Frere Hospital. There were only two full-time officers and one doctor doing two 2-hour sessions in the mornings while Livingstone Hospital's ICU made constant requests for tracheostomy procedures. Livingstone Hospital ICU chief, Dr Lizette van der Merwe, said she was desperate for a full-time ENT surgeon. Her 16 beds saw about 60 admissions per month with major delays in discharging patients who had been on mechanical ventilation for longer periods - a direct result of the long delays in getting tracheostomies done.

\section{Dr Peter Alexandris has seen seven fellow anaesthetists leave since January (of his total complement of 26). With no applicants appointed to replace them, elective services had been cut by a quarter to fulfil emergency service obligations while their training programme had suffered 'enormously'.}

Emergency Medicine Head at Livingstone Hospital, Dr C Snyman, writes that from 1 July only 'priority one' patients would be attended to by his skeleton staff. 'The rest will have to wait,' he says. Anaesthetics Acting Chief at the PEPHC (serving all three hospitals), Dr Peter Alexandris, has seen seven fellow anaesthetists leave since January (of his total complement of 26). With no applicants appointed to replace them, elective services had been cut by a quarter to fulfil emergency service obligations while their training programme had suffered 'enormously'. The rural outreach programme - instrumental in lowering maternal deaths had been stopped until there were sufficient doctors to maintain service delivery in the PE Metropole. Alexandris added: 'The current situation that has been left to develop will have far-reaching consequences for the general public and immediate action is needed to limit this disastrous situation

\section{Her team has so far paid} R30 000 out of their own pockets for patient transport so that some of those requiring daily radiation can complete treatment. (Transport for patients on daily radiation was suddenly stopped on 31 January this year.)

Ophthalmology Department joint chief for the PE hospital complex, Dr Mark Jacoby, describes his situation as 'fragile, as we are dependent on support services such as anaesthetics. Should they curtail their services we will be adversely affected'. He predicts that over the next six months a third of their junior staff will transfer to other institutions and will need replacing.

Head of Radiation Oncology for the PEPHC, Dr Erika R Jansen, does the work of four and a half consultants (seeing 1400 new patients per year, the recommended South African figure being one consultant per 300 new patients annually). She's working 10-hour weekdays and varying hours on Sundays and has been waiting over three months for a colleague to be appointed, let alone an intern medical physicist working but not re-appointed after her contract expired on 1 July this year. Her patient queue regularly exceeds 100 people, with some waiting up to eight hours. Her team has so far paid R30 000 out of their own pockets for patient transport so that some of those requiring daily radiation can complete treatment. (Transport for patients on daily radiation was suddenly stopped on 31 January this year.) She needs four consultants and 10 registrars/MOs/Comserves to 'turn this into a sustainable service'.

Izindaba has learnt of a major confrontation looming between Bhisho and a small minority of consultants it believes are cutting their public sector theatre times and teaching obligations in favour of
Remuneration for Work Outside the Public Service (RWOPS).

\section{Stop press: Murder attempt on Pillay}

Siva Pillay revealed that there was a nocturnal attempt on his life about four months ago when a motorcyclist fired two shots at him while he was travelling between East London and King William's Town, just before the Mdantsane turnoff. It is the latest in a series of verbal and physical threats made since he began an internal 'clean-up', forcing the dismissal or resignation of 1300 health department staffers for corruption and fraud over the past two years. ${ }^{2,3}$ The murder attempt was bungled by the right-handed biker having to unhand the throttle to draw and aim his pistol as he came alongside Pillay. The bullets penetrated and grazed the rear side of the vehicle. Police have opened an attempted murder docket but arrests are considered unlikely. The latest scams involve R100 000 in irregular procurements for the East London Emergency Medical Services and the identity theft of some 20 health department employees, including a dozen doctors, by what is believed to be a Nigerian syndicate with tentacles into several Eastern Cape government departments. The latter swindle involves 'testing' false credit cards with small transactions which, if approved, lead to multiple costly purchases, both on the Internet and face-to-face. Pillay acted quickly to avoid putting the entire departmental data base at risk, using his multi-agency task team to set up a hightech 'sting' operation and identify HR staff behind the internal leak. Police raided a deserted home in East London and seized computers with software to falsify ID books plus incriminating e-mails. At the time of writing there was only one arrest of a person using a doctor's documents to make small purchases, but it resulted in invaluable leads and the police raid.

\section{Chris Bateman}

chrisb@hmpg.co.za

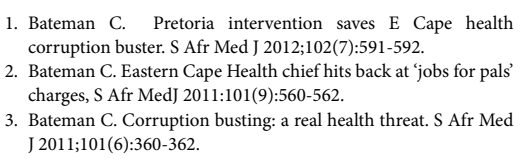
corruption buster. S Afr Med J 2012;102(7):591-592. 2. Bateman C. Eastern Cape Health chief hits back at 'jobs for pals' charges, S Afr MedJ 2011:101(9):560-562.

3. Bateman C. Corruption busting: a real health threat. S Afr Med J 2011;101(6):360-362

S Afr Med J 2012;102(9):720-722.

DOI:10.7916/SAMJ.6173 